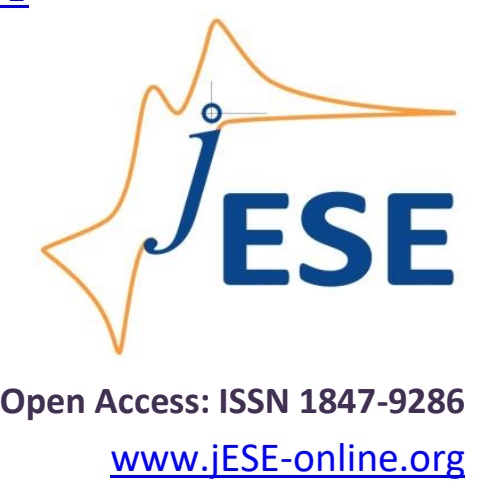

Original scientific paper

\title{
Parametric modeling of microbial fuel cells
}

\author{
Amandeep Singh and Balaji Krishnamurthy ${ }^{\square}$ \\ Department of Chemical Engineering, BITS Pilani, Hyderabad 500078, India \\ Corresponding author: ${ }^{\bowtie}$ balaji.krishb1@gmail.com \\ Received: February 27, 2019; Revised: March 27, 2019; Accepted: April 2, 2019
}

\begin{abstract}
Microbial fuel cells use bacteria to generate electrical energy and are used for lower power density applications. This paper studies the effect of operational parameters on the performance of a microbial fuel cell. The effect of length of the anode compartment, inlet acetate concentration, acetate flow rate, temperature, thickness of the membrane and bio-film conductivity on the performance of the fuel cell is modeled. The thickness of the membrane is found to play a very limiting role in affecting the performance of the fuel cell. However, the length of the anode compartment, acetate flow rate and bio-film conductivity are found to play a significant role in the performance of the fuel cell. Model results are compared with experimental data and found to compare well.
\end{abstract}

\section{Keywords}

Microbial fuel cell; hydrogen; bio-film; acetate; carbon dioxide; model

\section{Introduction}

Microbial fuel cells (MFCs) are multiphase systems involving biological and electrochemical processes to generate energy. These fuel cells convert chemical energy to electrical energy by the action of microorganisms. Most MFC's are constructed using a bio-anode, bio-cathode and a membrane separating two compartments. MFCs can be divided into two categories; mediated and unmediated. A mediated MFC uses a chemical (mediator) that transfers electrons from the bacteria in the cell to the anode. Unmediated MFC uses electrochemically active bacteria to transfer electrons directly to the anode. MFCs have started to find their usage in wastewater treatment. Modeling the effect of operational and design parameters on the performance of MFCs is critical for enhancing the performance of these fuel cells.

The MFC performance expressed in terms of the polarization curve is affected by several factors, including rates of fuel oxidation, resistance of the circuit, size of the anode compartment, transport of protons through the membrane to the cathode, membrane thickness (resistance), oxygen supply, and the reduction reactions at the cathode. Mathematical models help in studying the effect of 
these operational parameters on the performance of MFC. Quite a few models exist in the literature which studied the effect of operational parameters on the performance of MFC. The models which were developed to study MFC behavior can be primarily divided to anode based models and full cell models (which are focusing on both the anode and cathode).

\section{Anode based models}

Zhang and Halme [1] have developed one-dimensional anode model based on double chamber configuration. Picioreanu and Scott [2] have developed a two-dimensional model to understand the anode microbial activity. The authors studied the relation between the growing bio-film thickness and the current output. Marcus et al. [3] have proposed one-dimensional dynamic conduction based model to study the performance of MFC. The model postulates that conductivity of the bio-film is the major factor in a MFC performance. In both above references, the authors postulated that anode is the limiting factor in a MFC performance. Merkey and Choop [4] created a two-dimensional model to study the relationship between power output and the geometry of the cell. The model simulates the effect of bristle anodes and the way they should be placed in a grid and act on the energy output. Sedaqatvand and Mardanpoura [5] extended Marcus's model with a genetic algorithm which sought to minimize the difference between simulated and experimental data. Jayasinghe and Madhavan [6] simulated an MFC anode using a respiring bio-film. While the active bio-film invests the energy arising from the oxidation of the substrate, the respiring zone is in charge of energy conservation at the anode surface. Pinto et al. [7] have modeled the anode of a MFC using different degradation mechanisms for decomposition of acetate substrate.

\section{Models focused both on anode and cathode}

Oliviera et al. [8] have developed 1-d mathematical model to study the temperature variation in a MFC. The authors also studied the effect of bio-film thickness on the MFC performance. Cheng et al. [9] have developed a mathematical model to simulate the power loss and the potential drop caused by ohmic resistance of the carbon mesh. Zeng et al. [10] have developed a mathematical model for a two-chamber MFC which studies the dynamic behavior of MFC. The authors suggested that the cathodic reaction is the most significant limiting factor in MFCs. Cai and Liu [11] have studied effects of bio-film porosity and external resistance on the performance of a MFC. The authors postulated that at the startup phase, bio-film porosity plays a crucial role in electricity generation. However, at the steady phase, bio-film porosity plays no role in electricity generation. Mardanpour et al. [12] have studied the performance of a MFC as a function of bacterial transport parameters, bacteria activity, substrate variation, etc. The authors postulated that as the hydraulic diameter of the microchannel decreases, the power generation of the microfluidic MFC increases. $\mathrm{Ou}$ and Mench [13] have studied the effect of species diffusion and electrical migration on the performance of a MFC. The authors postulated that the electric field migration has a minimal impact on the performance of MFC. Sobieszuk et al. [14] have studied influence of operational parameters on the MFC performance. The authors have shown that the hydraulic retention time is the most important parameter affecting the effectiveness of MFCs. Yao and Li [15] have developed twodimensional model to study the MFC performance. The authors postulated that the electrical conductivity of the bio-film plays an important role in the MFC performance. Xia at al. [16] wrote a comprehensive review on MFCs. The authors qualified various models describing MFCs as the mechanism based models, bulk liquid models, electrochemical models, bio-film models, electrical models and application based models. Gadkari and Sadhukhan [17] presented a review on the mathematical models describing bio-electrochemical systems. Along with reviewing the 
conventional models for a study of bio-electrochemical systems, the authors have also reviewed new models such as microbial electrolysis cell, microbial electro-synthesis and microbial desalination cell. Capadaglio et al. [18] developed a mathematical model to study the application of MFC in wastewater treatment. The authors have reviewed the reactor configuration, electrochemical and microbiological characterization and operational schemes in the simulation of the MFC usage in wastewater treatment. While the above mentioned models already reported in the currently available and MFC related literature, give an overall perspective about the modeling work, we are primarily focused on developing of an anode model to study the effect of design and operational parameters on the performance of a MFC.

The focus of this paper is to study the effect of operational parameters on the performance of the MFC seen through a polarization curve (cell voltage vs. current density) properties. The decrease in the fuel cell voltage is due to over-potential losses due to activation, ohmic losses and concentration polarization. Concentration polarization losses occur at high current densities due to mass transport limitations. Ohmic losses are primarily seen in the middle of the current density range. These are losses due to the resistance of the membrane, bio-film, etc. Activation losses are usually seen at the beginning of the polarization curve where over-potential losses take place to enable the reaction to happen. Therefore, the objective of this paper is to study the effect of operational parameters of MFC on polarization curves and thereby on the fuel cell performance.

\section{Model development}

MFC can be considered as a reactor which transfers the chemical energy stored in an organic substrate into electricity due to the activity of enzymes/organisms. A schematic representation of the MFC is shown in Figure 1 (marks are explained within Nomenclature section). The fuel cell consists of an anode chamber with an electron current collector, a polymer electrolyte membrane and a cathode chamber with an electron current collector. The anolyte fuel, acetate reacts at the anode side with the bacteria to produce carbon dioxide and hydrogen ions. The carbon dioxide moves to the anode exit, while hydrogen ions diffuse across the membrane to the cathode. On the cathode side, the oxygen ions react with hydrogen to form water which is removed from the cathode.

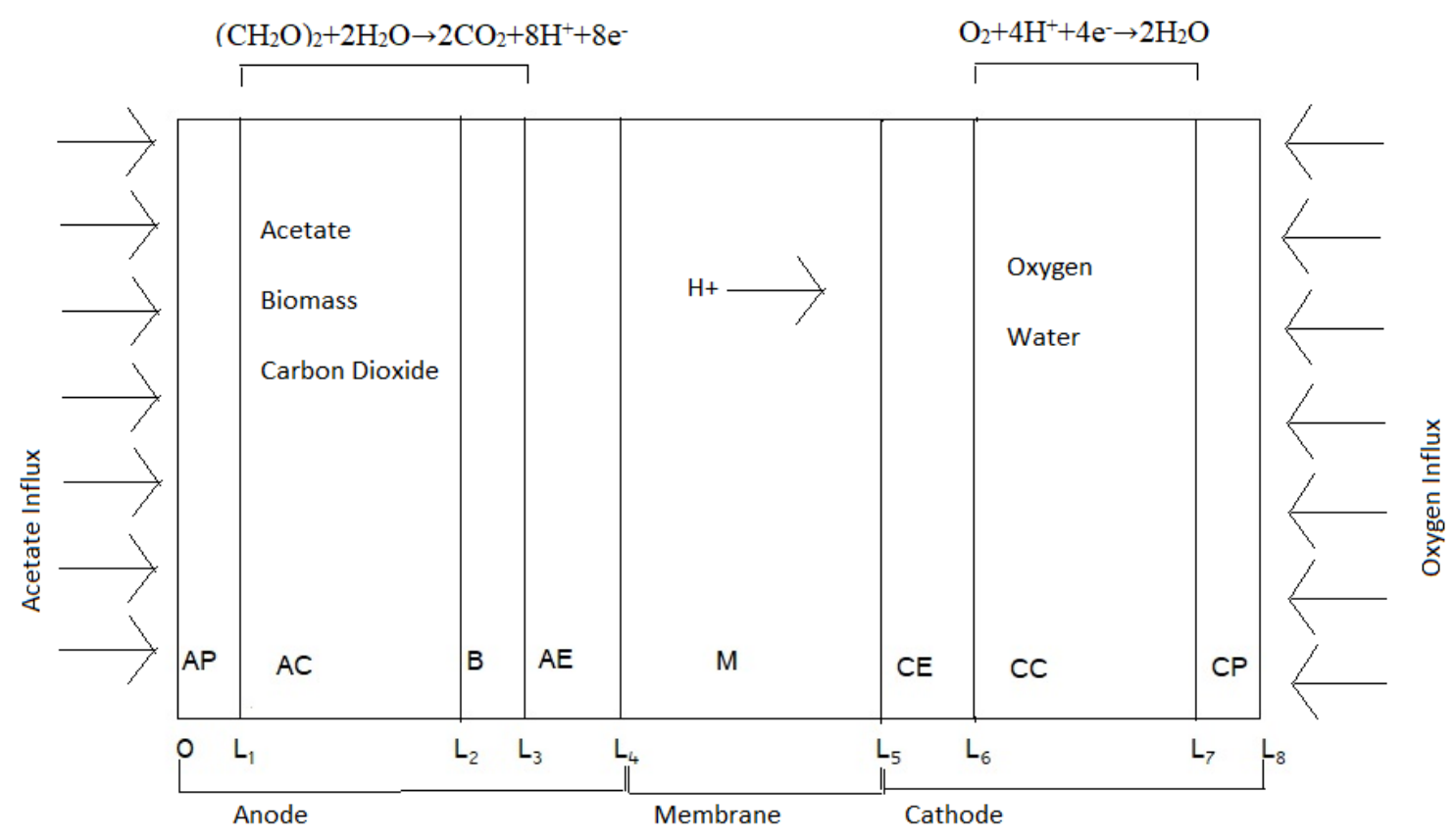

Figure 1. Schematic of a microbial fuel cell (MFC) 
The transfer of electrons to the anode occurs by two mechanisms; a mediated electron transferMET and direct electron transfer-DET. The anode and cathode reactions containing acetate as the substrate [1] are given by:

$$
\begin{aligned}
& \left(\mathrm{CH}_{2} \mathrm{O}\right)_{2}+2 \mathrm{H}_{2} \mathrm{O} \rightarrow 2 \mathrm{CO}_{2}+8 \mathrm{H}^{+}+8 \mathrm{e}^{-} \\
& \mathrm{O}_{2}+4 \mathrm{H}^{+}+4 \mathrm{e}^{-} \rightarrow 2 \mathrm{H}_{2} \mathrm{O}
\end{aligned}
$$

The overall reaction is given by:

$$
\left(\mathrm{CH}_{2} \mathrm{O}\right)_{2}+\mathrm{O}_{2} \rightarrow 2 \mathrm{CO}_{2}+2 \mathrm{H}_{2} \mathrm{O}
$$

\section{Assumptions}

1. Kinetics of the reactions on the anode is represented by Tafel and Monod equations. The Monod equation is typically given by:

$$
\mu=\mu_{\text {max }} \frac{S}{K_{\mathrm{S}}+S}
$$

where $\mu$ is the specific growth rate of the microorganisms, $\mu_{\max }$ is the maximum specific growth rate of the microorganisms, $S$ is the concentration of the limiting substrate for growth and $K_{\mathrm{s}}$ is the half velocity constant. The Monod equation describes substrate oxidation and microorganism growth. The units of $\mu, S$ and $K_{\mathrm{s}}$ are time ${ }^{-1}$, (mol/volume) and (mass/volume), respectively.

2. The oxygen reduction reaction at the cathode is governed by Tafel equation given by:

$$
E-E_{\text {eq }}=\frac{R T}{(1-\alpha) n F} \ln \frac{i}{i_{0}}
$$

where $i$ and $i_{0}$ are the current and exchange current densities for the oxygen reduction reaction.

3. The thickness of the bio-film is considered to be constant during simulations. This means that the overall rate of microbial growth through substrate utilization and the overall rate of bio mass loss are in equilibrium.

4. The transport of reactant species through the film is considered as one dimensional.

5. The effect of convection in the transport of reactant species in the bio-film and to the electrodes is neglected. The transport of reactant species in the bio-film and to electrodes is assumed to be diffusion, what means that Fick's diffusion laws can be used to evaluate the transport of these species.

6. Only hydrogen ions are considered to be transported across the membrane. Carbon dioxide, acetate, oxygen and water are assumed not transported across the membrane.

7. Anode and cathode compartments are modeled as a continuous stirred tank reactor-CSTR. This means that mass transport equations are primarily developed from CSTR equations. The mass balance at the anode takes into account rates of reaction in the anode compartment, bio-film and at the electrode.

8. The carbon dioxide is considered to be dissolved in solution. Hence the effect of $\mathrm{CO}_{2}$ in the gas phase is considered negligible.

\section{Model equations}

Given that the anode compartment is modeled as CSTR, the transient mass balance equation is given by:

$$
\frac{\mathrm{d} m}{\mathrm{~d} t}=m_{\mathrm{in}}-m_{\mathrm{out}}+m_{\mathrm{rxn}}
$$


In Eq. (4), $m_{\text {rxn }}$ represents the mass of reacting species, while $m_{\text {in }}$ and $m_{\text {out }}$ represent the mass of species entering and leaving the system.

The mass balance of acetate is given by [10]:

$$
\frac{\mathrm{d} c_{\mathrm{a}}}{\mathrm{d} t}=\frac{q}{V^{\mathrm{AC}}}\left(c_{\mathrm{a}}^{0}-c_{\mathrm{a}}^{\mathrm{AC}}\right)-r_{\mathrm{a}}
$$

The reaction rate of acetate oxidation (degradation) in the anode compartment defined by Eq. (1) is given by:

$$
r_{\mathrm{a}}=k \exp \left(\frac{\alpha_{\mathrm{a}} \eta_{\mathrm{a}} F}{R T}\right)\left(\frac{c_{\mathrm{a}}^{\mathrm{AC}}}{K_{a}+c_{\mathrm{a}}^{\mathrm{AC}}}\right) c_{\mathrm{x}}
$$

In Eq. (6), $k$ represents the rate constant, $c_{\mathrm{a}}{ }^{\mathrm{AC}}$ represents the concentration of the acetate in the anode compartment and $c_{x}$ represents the concentration of the bio-mass in the anode compartment. $\eta_{\mathrm{a}}$ represents the anodic over-potential and $K_{\mathrm{a}}$ represents the half velocity rate constant for acetate.

The transient equations for the acetate mass balance in the anode compartment is obtained by inserting eq. (6) into eq. (5):

$$
\frac{d c_{a}}{d t}=\frac{q}{V^{\mathrm{AC}}}\left(c_{\mathrm{a}}^{0}-c_{\mathrm{a}}^{\mathrm{AC}}\right)-k \exp \left(\frac{\alpha_{\mathrm{a}} \eta_{\mathrm{a}} F}{R T}\right)\left(\frac{c_{\mathrm{a}}^{\mathrm{AC}}}{K_{a}+c_{\mathrm{a}}^{\mathrm{AC}}}\right) c_{\mathrm{x}}
$$

The first term on the right hand side represents the mass flux of acetate in the anode compartment and the second term represents the reaction rate of acetate in the anode compartment. The reaction of acetate to form $\mathrm{CO}_{2}$ is a bio-electrochemical reaction; the electrochemical part of the reaction is dealt with Tafel equation and the bio-chemical reaction is dealt with Monod equation.

The acetate flux in the bio-film layer can be written as:

$$
N_{\mathrm{A}}=-D_{\mathrm{A}}^{\mathrm{B}} \frac{\mathrm{d} c_{\mathrm{ab}}}{\mathrm{d} x}
$$

Eq. (8) assumes that the transport of acetate ions in the bio-film is a result of diffusive flux. The acetate ions are not a charged species (effects of potential are neglected) and the convective flux is neglected. The transient differential mass balance equation for any species is given by:

$$
\frac{\partial c_{\mathrm{a}}}{\partial t}=-\frac{\mathrm{d} N_{\mathrm{a}}}{\mathrm{d} x}-r
$$

where the right side part represents the flux term and the reaction term.

Following Eq. (9), the transient equation for acetate mass balance in the bio-film is given by:

$$
\frac{\mathrm{d} c_{\mathrm{ab}}}{\mathrm{d} t}=D_{\mathrm{A}}^{\mathrm{B}} \frac{\mathrm{d}^{2} c_{\mathrm{ab}}}{\mathrm{d} x^{2}}-k \exp \left(\frac{\alpha_{\mathrm{a}} \eta_{\mathrm{a}} F}{R T}\right)\left(\frac{c_{\mathrm{a}}^{\mathrm{AC}}}{K_{\mathrm{a}}+c_{\mathrm{a}}^{\mathrm{AC}}}\right) c_{\mathrm{x}}
$$

\section{Transport equations for the cathode}

The oxygen mass balance in the cathode compartment is given by [1]:

$$
\frac{\mathrm{d} c_{\mathrm{O}_{2}}}{\mathrm{~d} t}=\frac{q^{\mathrm{CF}}}{A^{\mathrm{CC}}}\left(c_{\mathrm{O}_{2}^{0}}-c_{\mathrm{O}_{2}}^{\mathrm{CC}}\right)+D_{\mathrm{O}_{2}} \frac{\mathrm{d}^{2} c_{\mathrm{O}_{2}}}{\mathrm{~d} x^{2}}
$$

The equation for the cell potential is given by [1]:

$$
V_{\text {cell }}=E_{\text {cell }}-\eta_{\mathrm{a}}-\eta_{\mathrm{c}}-I_{\text {cell }} R_{\text {cell }}
$$


In Eq. (12), $\eta_{\mathrm{a}}$ and $\eta_{\mathrm{c}}$ are anode and cathode over-potentials and the last term refers to the ohmic loss due to the membrane resistance.

The membrane resistance $R_{\text {cell }}[8]$ is given by:

$$
R_{\text {cell }}=\frac{T^{\mathrm{M}}}{\sigma}
$$

In Eq. (13), $T^{\mathrm{M}}$ is the membrane thickness and $\sigma$ is the ionic conductivity of the membrane. The concentration of the acetate at the anode electrode/membrane interphase and the concentration of the oxygen at the cathode electrode/membrane interphase are assumed to be zero.

\section{Numerical solution}

For analysis of different parameters, it is necessary to choose a method that is efficient and provides high convergence. The partial derivatives terms were transformed into algebraic terms using central difference and transient PDE were converted into transient ODE. They were then solved using MATLAB function ODE15s.

Simple 1-D mesh was used and it was made enough fine that convergence is achieved. Optimal node number was calculated on the basis of order of length involved by trial and error.

\section{Results and discussion}

\section{Anode compartment length}

Figure 2 shows a time variation of the cell current density for different anode compartment lengths varying from 0.1 to $0.025 \mathrm{~m}$. It is seen that the cell current density increases with increasing length of the anode compartment (if the area is kept constant, this indicates an increasing volume of the anode compartment). For a given constant feed, Figure 2 indicates that the length of the anode compartment plays a key role in the performance of the MFC.

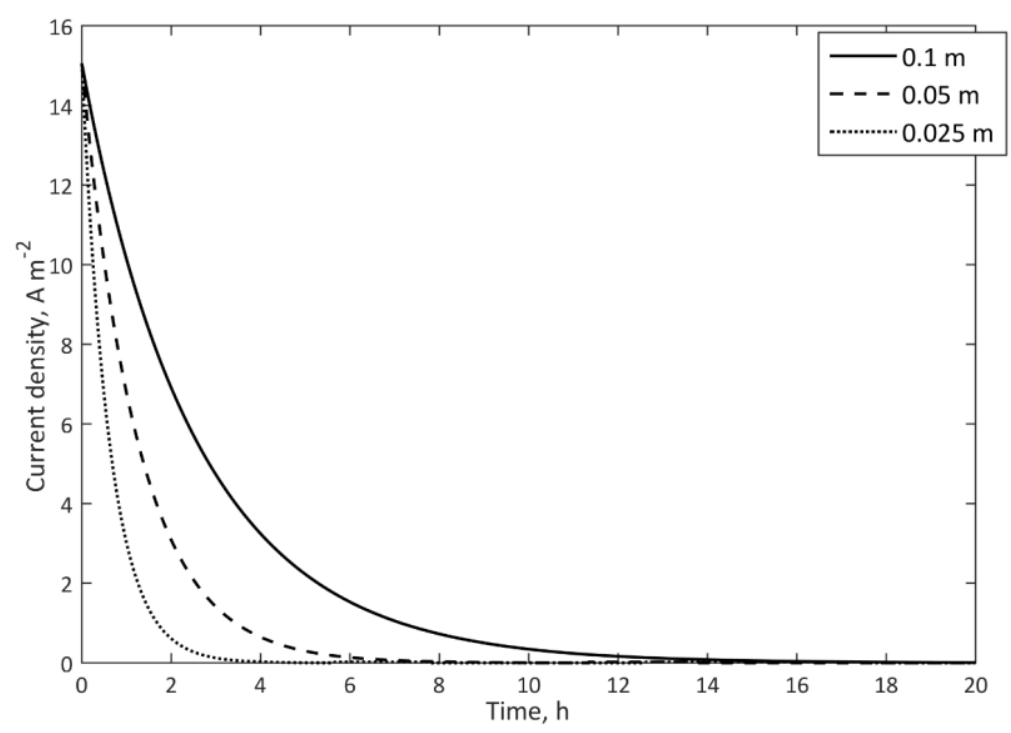

Figure 2. Time variation of current density for different lengths of anode compartment

A higher length of the anode compartment indicates a higher reactor volume which drives the reaction rate. This decreases the activation over-potential, what is seen through the highest current density observed when the anode compartment thickness is $0.1 \mathrm{~m}$. However, a large reactor volume also ensures that the concentration polarization is lower (at high current densities). This implies that when the anode compartment length is higher, presence of the excess reactant ensures that current 
can be drawn at extended time values. Lorant et al. [19] have studied the effect of the cathode to anode surface ratio on the performance of MFC. The authors predicted that with increasing cathode/anode surface area, the power density of a MFC increases, indicating that the oxygen reduction reaction is the rate limiting step in a MFC. Very little work has been done on understanding the effect of the anode surface area on the overall performance of a MFC. However, our results indicate that the anode surface area plays a significant role in the MFC performance. Table 1 indicates the list of parameters used for simulation.

Table 1. Table of model parameters taken from $[8,10]$ for simulating graphs in Figures 2-9

\begin{tabular}{ll}
\hline$q_{\mathrm{af}}$ & $2.25 \times 10^{-5} \mathrm{~m}^{3} \mathrm{~h}^{-1}$ \\
\hline$V^{\mathrm{AC}}, V^{\mathrm{CC}}$ & $5.5 \times 10^{-5} \mathrm{~m}^{3}$ \\
\hline$C_{\mathrm{A}}{ }^{0}$ & $1.56 \mathrm{~mol} \mathrm{~m}^{-3}$ \\
\hline$k$ & $0.207 \mathrm{~mol} \mathrm{~m}^{-3} \mathrm{~h}^{-1}$ \\
\hline$\alpha_{a}$ & 0.051 \\
\hline$T_{0, T_{\mathrm{C}}}$ & $303 \mathrm{~K}$ \\
\hline$T^{\mathrm{AF}}, T^{\mathrm{CF}}$ & $303 \mathrm{~K}$ \\
\hline$K_{\mathrm{A}}$ & $0.592 \mathrm{~mol} \mathrm{~m}^{-3}$ \\
\hline$C^{\mathrm{x}}$ & $0.4 \mathrm{~mol} \mathrm{~m}^{-3}$ \\
\hline$A^{\mathrm{S}}$ & $5 \times 10^{-4} \mathrm{~m}^{2}$ \\
\hline$C_{\mathrm{O} 2}{ }^{0}$ & $(0.21 \times P) /(R \times T) \mathrm{mol} \mathrm{m}^{-3}$ \\
\hline$q^{\mathrm{C}}$ & $1.11 \times 10^{-3} \mathrm{~m}^{3} \mathrm{~h}^{-1}$ \\
\hline$\alpha_{\mathrm{C}}$ & 0.44 \\
\hline$E_{\mathrm{cell}}$ & $0.77 \mathrm{~V}$ \\
\hline$\sigma$ & $3.6 \mathrm{~S} \mathrm{~m} \mathrm{~m}^{-1}$ \\
\hline$T_{\mathrm{M}}$ & $1.778 \times 10^{-4} \mathrm{~m}$ \\
\hline
\end{tabular}

\section{Membrane film thickness}

Figures 3 and 4 show polarization curves of MFC for different membrane film thicknesses. It can be seen from Figure 3 that the membrane film thickness makes a very small impact on the performance of the fuel cell.

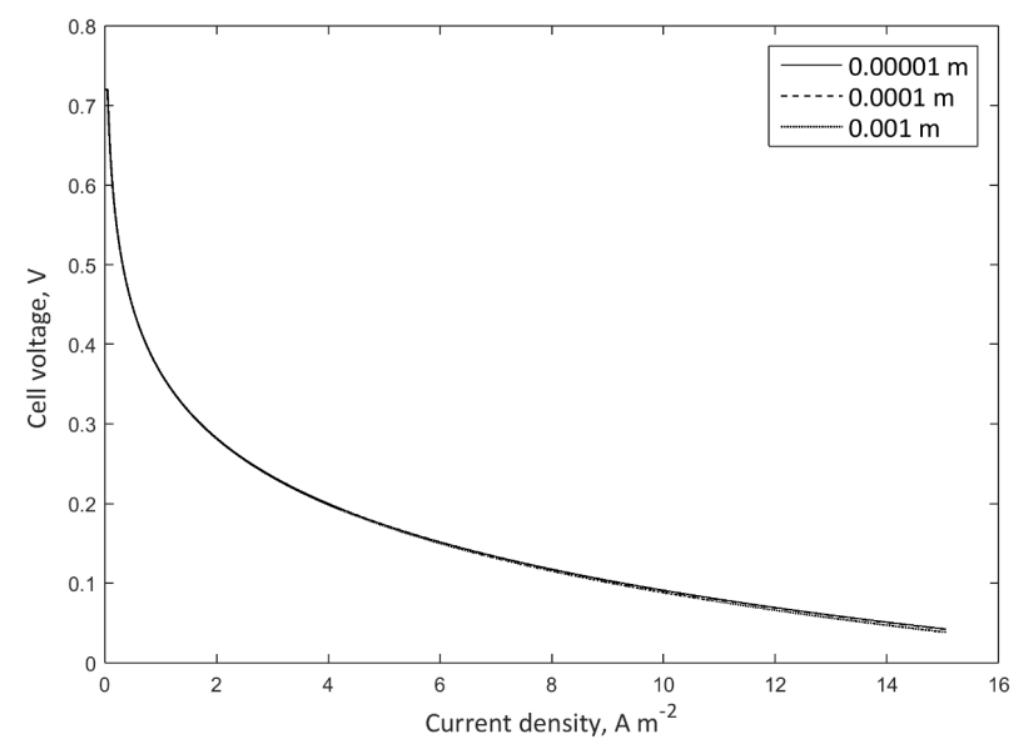

Figure 3. Effect of membrane thickness on MFC performance

Figure 4 shows the effect of the membrane film thickness in the high current density area. It is seen that the membrane film thickness (ohmic resistance) plays a marginal role in the high current density region. The relationship between membrane resistance and membrane thickness is given by 
Eq. (13), which shows that the ohmic resistance due to the membrane is defined as the ratio of the thickness of the membrane to the ionic conductivity of the membrane. Figures 3 and 4 indicate that if the ionic conductivity of the membrane is kept constant, the performance of the microbial fuel cell has little dependence on the thickness of the membrane. Consequently, keeping the thickness of the membrane constant, varying the ionic conductivity of the membrane has little effect on the performance of the fuel cell. This indicates that the transport of hydrogen ions through the membrane is more dependent on other factors like concentration flux of hydrogen ions, potential gradient across the cell and the diffusion coefficient of hydrogen ions.

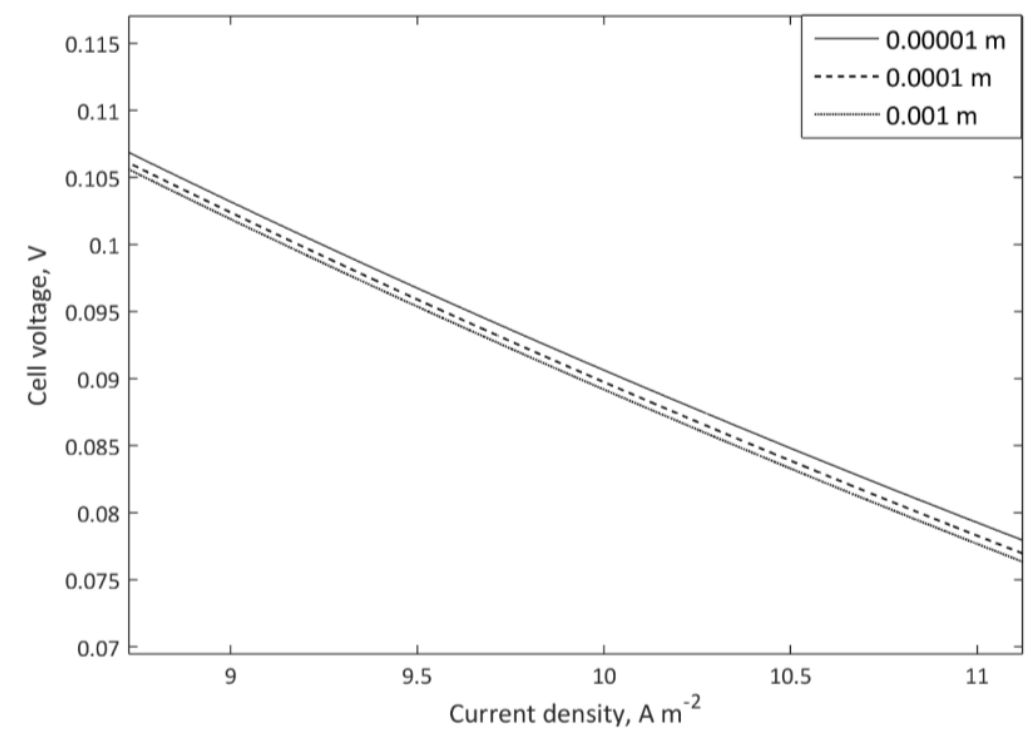

Figure 4. Effect of membrane thickness on MFC performance

\section{Bio-film conductivity}

Figure 5 shows the effect of bio-film conductivity on the performance of MFC. The figure indicates that the performance of a microbial fuel cell is affected very strongly by the bio-film conductivity. Whereas no effect of bio-film conductivity is observed on the activation part of the polarization curve, there seems to be a pronounced effect of bio-film conductivity in the high current density region of the polarization curve. Malvankar et al. [20] have suggested that extra cellular electron transfer via conductive bio-film is the most efficient mechanism for high current density MFCs. Increased bio-film conductivity lowers the resistance for electron transfer between the bio-film and the anode. It was also suggested that electron donor mass transfer resistance becomes significant at higher bio-film conductivity. The same authors [20] have further stated that the observed metallic like conductivity is associated with a network of microbial nanowires coursing through the bio-film. Some experimental studies [21-23] have indicated that the bio-film conductivity does not play a major role in affecting the current density in a microbial fuel cell while other studies [20,24] suggested otherwise. An earlier modeling study [13] has indicated that the bio-film conductivity plays a major role in affecting the fuel cell current density. According to Yao et al. [25], the conductivity of the bio-film directly affects a distribution of the solid potential. The authors postulated that the slope of the solid potential of the bio-film decreases with increase in conductivity which causes electrons to move more easily to the electrode surface. On the other hand, the liquid potential is a function of the bio-electrochemical reaction rate and increases with bio-film conductivity. Thus, increasing the bio-film conductivity increases the overall rate of the bioelectrochemical reaction, leading to increase in performance of MFC, particularly in high current density regions. 


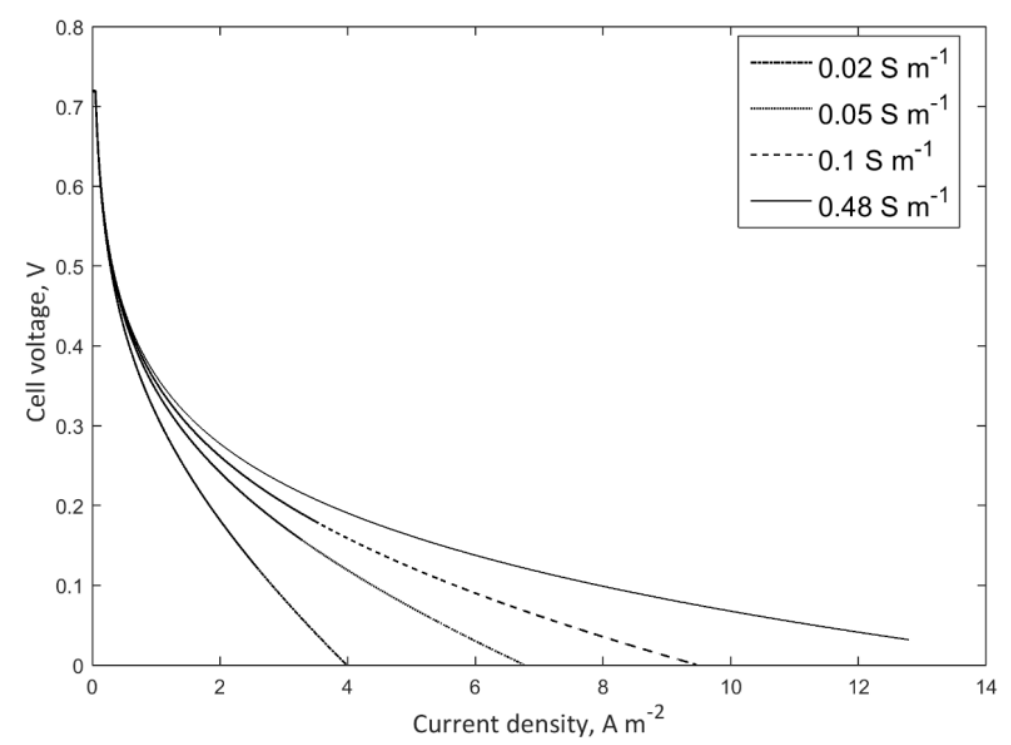

Figure 5. Effect of bio-film conductivity on MFC performance

\section{Effect of temperature}

Figure 6 shows that the performance of MFC is affected strongly by temperature. Increasing of temperature not only drives up anodic and cathodic reaction rates, but also increases diffusion of hydrogen ions to the cathode, increasing thus the cathodic reaction rates and leading to significant improvement of MFC performance.

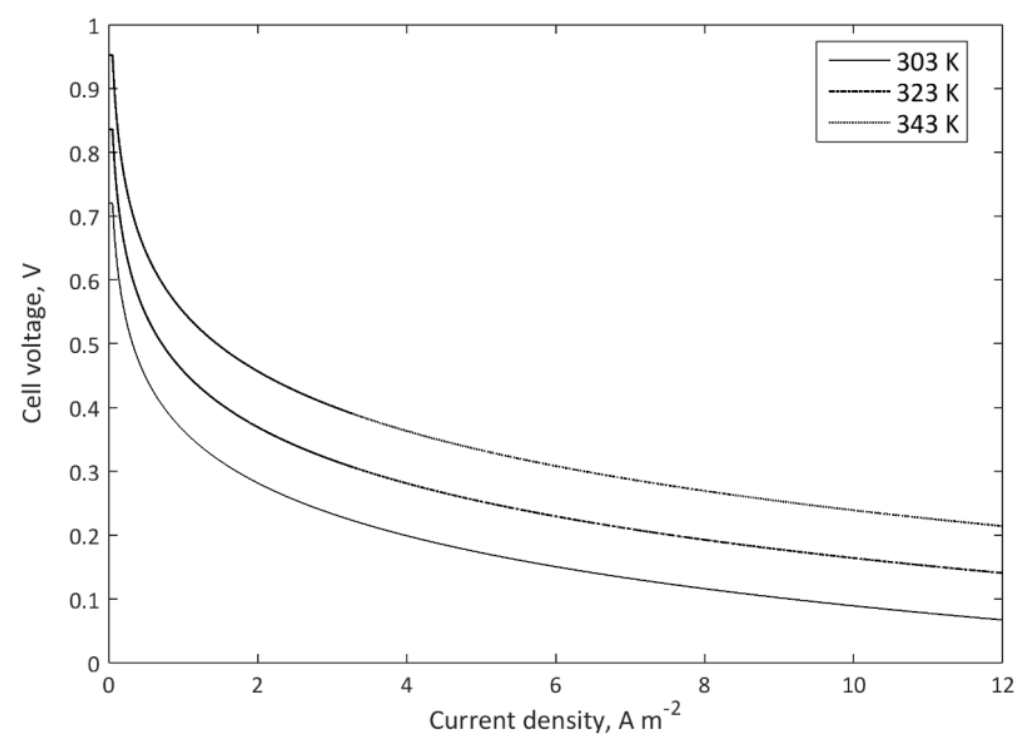

Figure 6. Effect of temperature on MFC performance

It seems that temperature shows somewhat higher impact in the lower current density region where the activation over-potential plays a major role, than in the higher current density region of the polarization curve. This has already been expected, since temperature plays a major role in affecting the rate constant and hence the rate of the reaction. Behera et al. [26] postulated that the internal resistance of $\mathrm{MFC}$ is the highest when the temperature is at $20^{\circ} \mathrm{C}$, than progressively decreases with increasing temperature up to $40^{\circ} \mathrm{C}$, and does not change much after $40^{\circ} \mathrm{C}$. However, our simulation results indicate that the performance of MFC increases with temperature beyond 40 ${ }^{\circ} \mathrm{C}$. Since the effect of temperature affects other factors, including reaction rates at the anode and 
cathode, it is very difficult to quantify the effect of temperature on the internal resistance of the cell using our simulation model.

\section{Effect of anode surface area}

Figure 7 shows the variation of current density for different inlet acetate concentrations, while Figure 8 shows the variation of current density at constant acetate concentration, but different anode surface areas. Combining these two graphs helps us to understand few results.

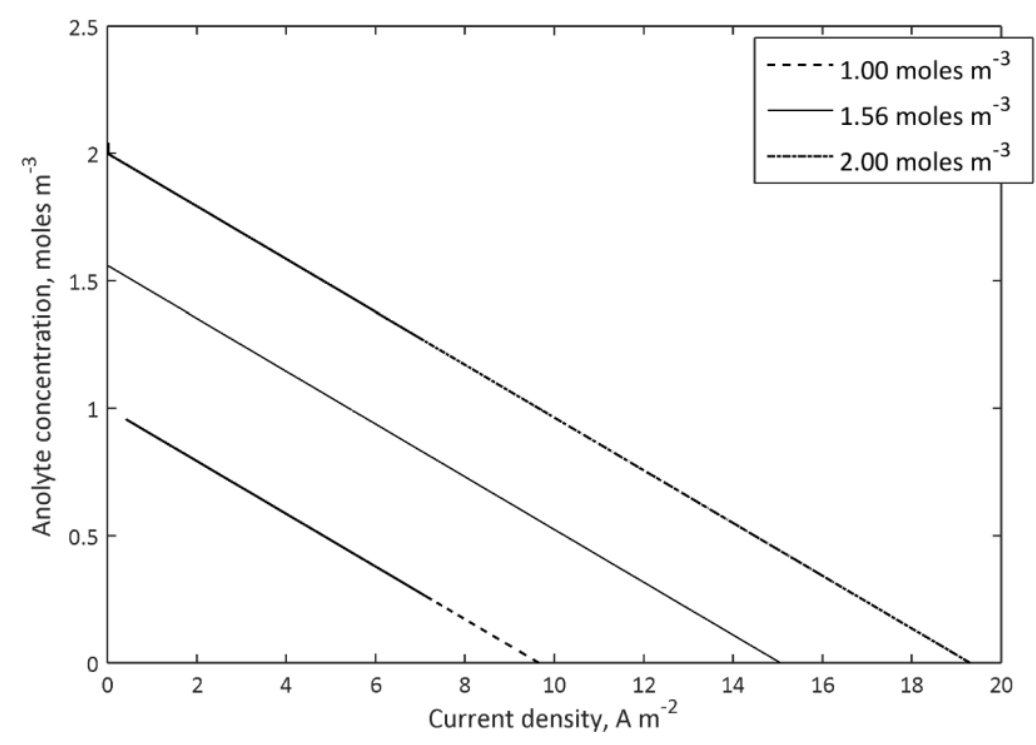

Figure 7. Effect of anolyte concentration on MFC performance

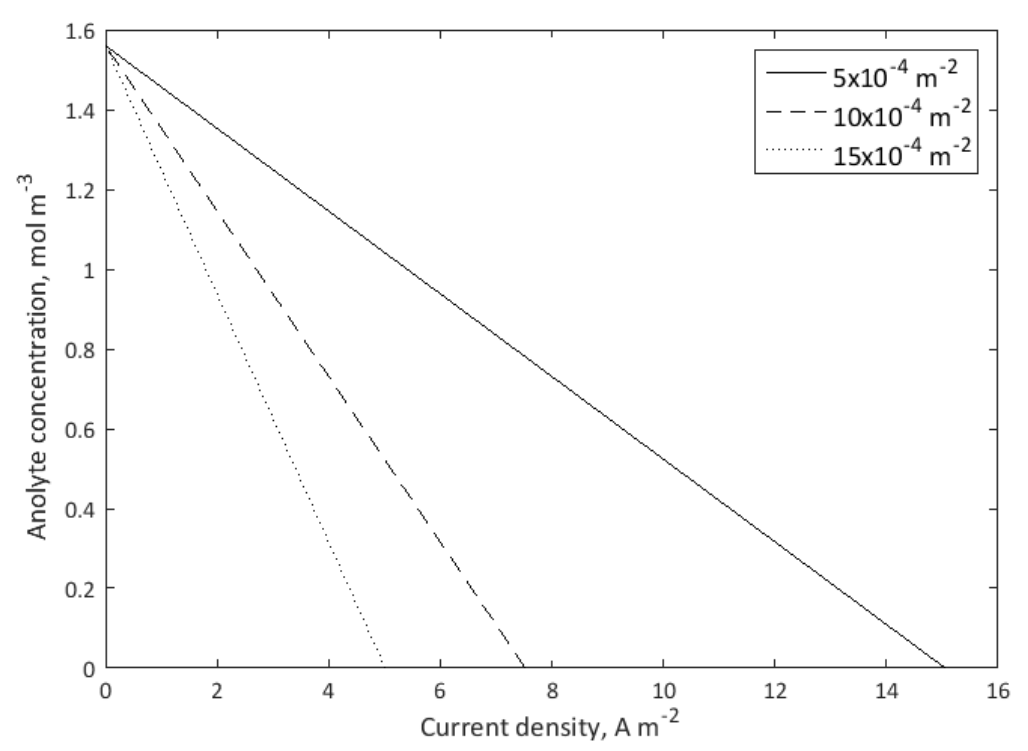

Figure 8. Effect of anode surface area on MFC performance

The inlet acetate concentration plays a significant role in the low current density region. This indicates that the concentration of the acetate plays significant role in lowering the activation overpotential at the anode side (since we are looking at acetate concentration only, the cathodic reaction is not taken into account). Figure 8 shows the variation of current density as a function of anode surface area for the given acetate concentration. The resulting graphs indicate that the area of the anode surface plays a major role in driving the current density in the high current density 
region (ohmic and concentration polarization regions). This indicates that $a$ higher anode surface area really enhances the current in the mass transfer limited regions, possibly due to higher reaction rates. Depending on the application of the microbial fuel cell, the fuel cell needs to be designed accordingly. Very little data is available on the effect of acetate concentration on the performance of MFC. Lorant et al. [19] proposed that efficiency of MFC can be fairly high at lower concentrations of acetate (what means that the power will not deteriorate rapidly at lower concentrations). Our simulation results indicate a similar effect.

\section{Comparison of modeling results with experimental data}

Figure 9 shows the comparison of modeling results with experimental data $[8,10]$. The parameters used for data fitting are summarized in Table 1 . The following parameters were considered in simulations: temperature, inlet acetate concentration, anode flow rate, cathode flow rate, volume of the anode compartment and membrane thickness. The simulation results seem to capture experimental trends very well. However, a certain discrepancy between the simulation results and the experimental data can be observed. This could be due to certain assumptions made in the model. The assumption of constant bio-film thickness is one factor which could affect simulation results, as well as neglecting the effect of convection on the performance of MFC. Although the effect of these assumptions could not be quantified, they could definitely affect the performance of a MFC.

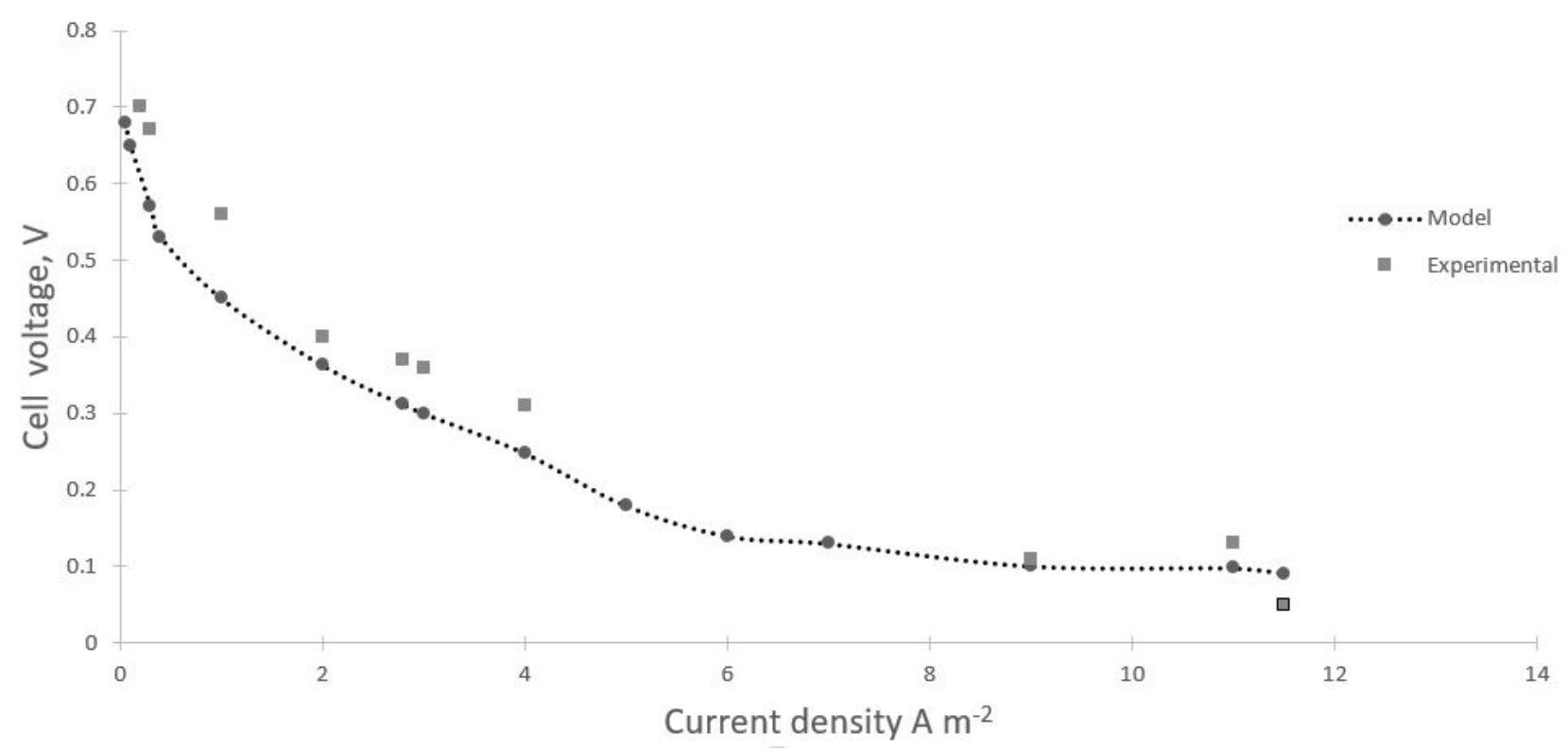

Figure 9. Comparison of simulation results with experimental data

\section{Conclusion}

A mathematical model is developed to study effects of operational parameters on the performance of a microbial fuel cell. The effect of thickness of the anode compartment, membrane resistance, bio-film conductivity and inlet concentration of the acetate on the performance of the microbial fuel cell is studied. The membrane thickness and resistance are found to have minimal effect of the MFC performance. However, bio-film conductivity is found to have a significant impact on the polarization curve, particularly in the high current density region. Increasing the area of the anode compartment seems to have a significant impact on the polarization curve in the high current region (mass transport limited region). Model results are compared with experimental data and found to compare well. 


\section{Nomenclature}

AC anode compartment

$\mathrm{AE} \quad$ anode electrode

AP anode acrylic plate

B bio-film

CC cathode compartment

CE cathode electrode

$\mathrm{CP} \quad$ cathode acrylic plate

$V_{\mathrm{AC}} \quad$ volume of the anode compartment, $\mathrm{m}^{3}$

$N_{\mathrm{A}} \quad$ flux of acetate in the bio-film layer, $\mathrm{mol} \mathrm{m}^{-2} \mathrm{~s}^{-1}$

$D_{\mathrm{A}}{ }^{\mathrm{B}} \quad$ diffusivity of the acetate in the bio film layer, $\mathrm{m}^{2}$

$A^{\mathrm{CC}} \quad$ area of the cathode compartment, $\mathrm{m}^{2} \mathrm{~s}^{-1}$

$c_{\mathrm{a}} \quad$ concentration of acetate in the anode compartment, $\mathrm{mol} \mathrm{m}^{-3}$

$c_{A}{ }^{0} \quad$ concentration of acetate at the entrance to the anode compartment, $\mathrm{mol} \mathrm{m}^{-3}$

$c_{a}{ }^{A C} \quad$ concentration of acetate at the exit of the anode compartment, $\mathrm{mol} \mathrm{m}^{-3}$

$\mathrm{Cab}_{\mathrm{ab}} \quad$ concentration of acetate in the bio-film, $\mathrm{mol} \mathrm{m}^{-3}$

$c_{a}{ }^{A B} \quad$ concentration of acetate at the bio-film/AE interface, $\mathrm{mol} \mathrm{m}^{-3}$

$\mathrm{C}_{2}$ concentration of oxygen in the cathode compartment, $\mathrm{mol} \mathrm{m}^{-3}$

$\mathrm{CO}_{2}{ }^{\mathrm{O}}$ concentration of oxygen at the $\mathrm{CP} / \mathrm{CC}$ interface, $\mathrm{mol} \mathrm{m}^{-3}$

$\mathrm{CO}_{2}{ }^{\mathrm{CC}}$ concentration of oxygen at the $\mathrm{CC} / \mathrm{CE}$ interface, $\mathrm{mol} \mathrm{m} \mathrm{m}^{-3}$

$C_{\mathrm{x}} \quad$ concentration of bio-mass in the anode compartment, $\mathrm{mol} \mathrm{m}^{-3}$

$F \quad$ Faraday constant, $94485, \mathrm{C} \mathrm{mol}^{-1}$

$K \quad$ rate constant of the reaction, $\mathrm{mol} \mathrm{m}^{-3} \mathrm{~h}^{-1}$.

$K_{\mathrm{A}} \quad$ half velocity rate constant for acetate, $\mathrm{mol} \mathrm{m}^{-3}$

$R \quad$ gas constant, $8.314 \mathrm{~J} \mathrm{~mol}^{-1} \mathrm{~K}^{-1}$

$R_{\text {cell }} \quad$ cell resistance due to membrane, $\Omega$

$T$ temperature, Kelvin

$v \quad$ volume, $\mathrm{m}^{3}$

$V_{\text {cell }} \quad$ cell voltage, $\mathrm{V}$

$T_{0} \quad$ wall temperature on anode side, $\mathrm{K}$

$T_{\mathrm{C}} \quad$ wall temperature on cathode, $\mathrm{K}$

$q$ flow rate, $\mathrm{m}^{3} \mathrm{~h}^{-1}$

$T_{\mathrm{M}} \quad$ membrane thickness, $\mathrm{m}$

$T^{\mathrm{AF}} \quad$ temperature of the anode stream

$T^{\mathrm{CF}} \quad$ temperature of the cathode stream

$A^{\mathrm{s}} \quad$ surface area of membrane, $\mathrm{m}^{2}$

E applied potential, $\mathrm{V}$

$E_{\text {eq }} \quad$ standard potential of the redox reaction (V)

$\alpha_{a} \quad$ anodic transfer coefficient

$\alpha_{c} \quad$ cathodic transfer coefficient

$\sigma \quad$ ionic conductivity of membrane, $\mathrm{S} \mathrm{m}^{-1}$

$\eta_{\mathrm{a}} \quad$ anode overpotential, $\mathrm{V}$

$\eta_{\mathrm{c}} \quad$ cathode overpotential, $\mathrm{V}$

Acknowledgements: We wish to acknowledge BITS Pilani, Hyderabad for their help in publishing this article. 


\section{References}

[1] X. C. Zhang, A. Halme, Biotechnology Letters 17 (1995) 809-814.

[2] C. Picoreanu, K. Scott, Water Research 41 (2007) 2921-2940.

[3] A. K. Marcus, C. I. Torres, B. E. Rittmann, Biotechnology and Bioengineering 98 (2007) 1171-1182.

[4] B.V. Merkey, D. L.Chopp, Bulletin of Mathematical Biology 74 (2012) 834-857.

[5] R. Sedaqatvand, M. M. Mardanpoura, Bioresource Technology 146 (2013) 247-253.

[6] N. Jayasinghe, R. Madhavan, BioTechnology Journal 10 (2014) 1350-1361.

[7] R. P. Pinto, B. Srinivasan, M. F Maneul, B. Tattarskosky, Bioresource Technology 101 (2010) 52565265.

[8] V. B. Oliviera, M. Simoes, L. F. Melo, A. M. F. R. Pinto, Energy 61 (2013) 463-471.

[9] S. Cheng, B. Wang, Y. Wang, Bioresource Technology 147 (2013) 332-337.

[10] Y. Zeng, Y. F. Choo, B. H. Kim, P. Wu, Journal of Power Sources 195 (2010) 79-89.

[11] W. Cai, Hong Liu, Chemical Engineering Journal 333 (2018) 672-582.

[12] M.M.Mardanpour, S.Yaghmaei, M.Kalantar, Journal of Power Sources 342 (2017) 1017-1031.

[13] S. Ou, M. M. Mench, Journal of Power Sources 314 (2016) 49-57.

[14] P. Sobieszuk, A. Jaraszewicz, L. Makowski, Journal of Power Sources 371 (2017) 178-187.

[15] S. Yao, X. Y. Li, Electrochimica Acta 212 (2016) 201-211.

[16] C. Xia, D. Zhang, W. Pedrycz, Y. Zhu, Y. Gao, Journal of Power Sources 373 (2018) 119-131.

[17] S.Gadkari, S. Gu, J. Sadhukhan, Chemical Engineering Journal 343 (2018) 303-316.

[18] A. Capadaglio, D. Cecconet, D. Molognoni, Processes 5 (4) (2017) 73-78.

[19] B. Lorant, M.Loka, G. M.Tardy, Energy (IYCE), (2015) 1-7.

[20] N. Malvankar, M. Tuominen, D. Lovely, Energy and Environmental Science 5 (2012) 5790-5796.

[21] H. Richter, L. M. Tender, Energy and Environmental Science 2 (2009) 506-516.

[22] C. I. Torres, A. K. Marcus, P. Parameswaran, B. E. Rittmann Environmental Science and Technology 42 (2008) 6593-6597.

[23] Y. Liu, H. Kim, R. Franklin, D. R. Bond, Energy and Environmental Science 3 (2010) 1782-1788.

[24] D. Pocaznoi, B. Erable, M.-L. Delia, A. Bergel, Energy and Environmental Science 5 (2012) 5287-5296.

[25] S. Yao, L. He, B. Song, Y. Li, Electrochimica Acta 212 (2016) 201-211.

[26] M. Behrera, P.S.Jana, M. M. Ghangrekar, Bioresource Technology 101 (2010) 1183-1189.

C2019 by the authors; licensee IAPC, Zagreb, Croatia. This article is an open-access article distributed under the terms and conditions of the Creative Commons Attribution license (http://creativecommons. org/licenses/by/4.0/) 